\title{
Genitourinary medicine, AIDS and the NHS Act: will contracting arrangements lead to contracted services?
}

\author{
C Bentley, $M$ W Adler
}

The fundamental review of the British National Health Service undertaken by the Government in 1988 produced recommendations for a restructuring of the Service around the principles of an internal market. One of the main aims stated in the resulting White Paper Working for Patients ${ }^{1}$ which spelt out the proposed changes was "... to give patients ... greater choice of the services available". Thus, one might expect services already offering free patient choice to flourish in the new environment. Genitourinary Medicine (GUM), an open access selfreferral service, is one such specialty. GUM has changed dramatically since the 1980 s under the impetus of the epidemics of the viral sexually transmitted diseases. These include human papilloma virus, hepatitis, herpes, and of course human immunodeficiency virus (HIV). As this latter epidemic, in particular, continues to expand, an increasing proportion of the population from a variety of client groups will need to contact the service, so it is vital that a wide choice of clinic services is maintained and even expanded accordingly. Will this be possible and will GUM/AIDS services thrive or wither under the new conditions established by the National Health Service Act (1990)?

Protecting the confidential, open access service When the spectre of contracting was first raised there had been considerable speculation that patients in need of emergency care away from their home district would be delayed or even turned away, if there was no contract covering their case. In order to overcome

Public Health Medicine Department, Bloomsbury and Islington Health Authority and Academic Department of Genito Urinary Medicine, University College and Middlesex School of Medicine, London W1N 8AA

C Bentley

Academic Department of Genito Urinary Medicine, University College and Middlesex School of Medicine, London W1N 8AA, UK

$M W$ Adler this, special arrangements were therefore devised at an early stage to cover Accident and Emergency (A\&E) departments. In essence it was stated that all patients attending A\&E departments would be covered by a single contract (between the local district purchasing authority and the provider unit) regardless of their district of residence. Having established this precedent the Department of Health were able to refer to it when the question of contracting for other self-referral services was raised.

In February 1990 the document Contracts for Health Services: Operating Contracts ${ }^{2}$ confirmed that ... "the essential objective is to guarantee choice for patients, particularly where services are provided on a walk-in basis". It continues "Unless alternative arrangements are agreed with RHAs (Regional Health Authorities), DHAs (District Health Authorities) will be expected to fund GUM clinics in the same way as Accident and Emergency services, i.e. by placing contracts which cover all patients who present for service, regardless of the district of residence". The contract is to be of the "block" type (see table) with payment in advance for access to a defined range of services.

$\mathrm{Up}$ to this point, however, there had been no clarification of the funding situation. DHA funding is to be based on a capitation allocation for residents only. Were districts going to be expected to pay for this care of non-residents attending walk-in services out of their limited budget? If so, many might opt not to maintain their services. When the guidance came, also in early 1990 , it was very cursory. In the Executive Letter "District Allocations" 3 it was suggested that, when allocating funds to districts, regions ". . . may wish to consider" extra funding for districts whose department sees significant numbers of tourists and commuters. No mention was made of self-referral services such as GUM clinics.

There was another important issue. A significant difference between GUM clinics and A\&E departments is the need in the former for anonymity and confidentiality. It has always been of great importance, in the interests of public health, that patients are not deterred from presenting by the embarrassment and stigma associated with others knowing that 
Table Types of contract outlined in "Working for Patients" documentation

\begin{tabular}{|c|c|c|}
\hline Type & Definition & Method of payment \\
\hline Block & $\begin{array}{l}\text { Access to a defined } \\
\text { range of services }\end{array}$ & $\begin{array}{l}\text { Annual fee in } \\
\text { instalments }\end{array}$ \\
\hline Cost and Volume & $\begin{array}{l}\text { Purchase of } \\
\text { episodes of care/ } \\
\text { procedures }\end{array}$ & $\begin{array}{l}\text { Annual fee in } \\
\text { advance }\end{array}$ \\
\hline Cost per case & $\begin{array}{l}\text { Price of individual } \\
\text { case or treatment }\end{array}$ & $\begin{array}{l}\text { Retrospective } \\
\text { billing }\end{array}$ \\
\hline
\end{tabular}

they have a sexually transmitted disease. With the advent of HIV infection and AIDS the consequences unfortunately extend beyond this, possibly threatening job, housing and insurance. If the full $A \& E$ model was applied to GUM services, patient anonymity might well be compromised. The Working for Patients guidance Operational Principles ${ }^{4}$ stated that any admission to hospital from the A\&E department would fall outside the "block" contract. Costs of the in-patient stay would, therefore, be recovered by billing the patient's district of residence, if it could not be fitted into an already established contract. This would, of course, mean that the confidentiality of AIDS patients would soon be compromised, since they frequently require hospital admission.

Realising that the A\&E model was not good enough on its own to cover the special needs of GUM services, the All-Party Parliamentary Group on AIDS tried to add a specific amendment on selfreferral services to the NHS Bill as it passed through the House of Lords. Although the amendment was not pushed through, the lobbying did produce some more specific statements from the Government on the subject. In particular, the two main issues discussed above were partly clarified in a speech made on behalf of the Government by Baroness Blatch in the House of Lords. ${ }^{5}$

The first concerned funding. With respect to budget allocations she stated: . . ."we expect RHAs to reflect the usage of self-referral services. Therefore the funding of DHAs will have to take into account $A \mathcal{E} E$ services as well as self-referral services for all comers as well as residents."

This statement is welcome since it will allow the major centres to be funded "up front" for their work for non-residents. However, it does not entirely solve the problem. As it stands, there is no incentive for districts to establish or maintain GUM, drug misuse service or family planning clinics for their own residents. If they do not run a service, residents will have to self-refer across the district boundary. The district of residence will then bear no financial costs either of running a service, or of repayment for episodes of care. For GUM services, at least, this potentially damaging situation for the public health is fortunately partly countered by the Department of Health supporting the recommendations of its Working Group which examined workloads in GUM clinics (the Monks Enquiry Report). This essentially makes GUM a "designated" service ${ }^{67}$ to be provided in all districts. This does not apply to drug misuse or family planning services.

The second important statement in Baroness Blatch's speech was: ... "The important point on confidentiality is that treatment will begin and end in one local authority. There will not be a cross-boundary flow of information back to the home authority of the patient who is receiving services."

The most important implication of this is that episodes of care which involve admission of AIDS patients and others to hospital through departments of GUM or drug misuse services will be the only ones whose non-residents will not be billed back to their district of residence. The question now arises about patients found to have HIV infection/AIDS after admission through $A \& E$ or another out-patient clinic. For the same reasons of confidentiality, these also should not be billed. These points have not yet been clarified so far in any generally circulated guidance from the Department of Health. When such guidance is issued, it is hoped that confidentiality is genuinely protected, and that it is not compromised for the convenience of fitting into management systems.

\section{Effects of the funding of HIV|AIDS services}

If there can be no cross-boundary flow of information about patients self-referring with HIV infection/ AIDS this precludes cost and volume contracts, and retrospective billing (table). All HIV/AIDS care must therefore, be covered by the single block contract open to all-comers. How can it be ensured that all the costs of what are often complex care packages are fully recovered?

"Working for Patients" documentation on costing and pricing of contracts makes two points very clear. ${ }^{8}$ (1) there will be no cross-subsidisation between contracts, (2) contract pricing must "cover all costs".

The only source of funding for (non-resident) clients with HIV infection/AIDS is currently the specifically earmarked or "ring-fenced" AIDS allocation. It therefore becomes necessary for this money to cover all costs of care. This will include out-patient costs, but also costs of in-patient care, including cross-specialty referrals, and costs of community care outreach teams. There has been no indication so far that the Department of Health have taken this into account.

Currently the ring-fenced money is allocated to regions for HIV/AIDS care according to a three part formula: 
(i) non-treatment services to all regions, based (HIV prevention)

(ii) drug misuse services

(iii) treatment and care costs per capita of residents to all regions based on separate per capita calculations number of live AIDS cases treated in each centre during previous year

Is this formula still appropriate in the new environment? If all costs are to be covered, for example, it must be considered whether a standard per capita allocation can be made for prevention services. There will be a marked differential between the costs of running programmes in the inner city as opposed to more rural areas. The former will have larger targets of people with high-risk behaviour. In addition, major foci of transmission, such as sex industry workers and illicit drug injectors, will require relatively high cost interventions, such as outreach and street contact teams. Similarly, the allocation of treatment and care costs currently depends on a standardised service average cost per AIDS case. This may not be appropriate for several reasons: Firstly, the number of AIDS cases is used as an indicator of the numbers of all patients with HIV infection. The use of anti-retroviral therapy and prophylaxis against opportunistic infections in persons with pre-AIDS will, however, change the balance of expenditure. More people may present for testing, and people at risk may present for testing earlier if there are perceived benefits by doing so. This will alter the ratio of AIDS/pre-AIDS cases. The ratio may also differ from centre to centre, and particularly between specialist and non-specialist units. This would be exaggerated if centres are successful in devolving care of AIDS patients back to districts of residence, thus being left with proportionately less AIDS cases. It might therefore act as a disincentive to carry this strategy through. Secondly, more resources for zidovudine, DDI, CD4 counts, monitoring and more frequent attendances will be spent on pre-AIDS cases, thereby altering the balance of costs. Thirdly, the number of AIDS cases presenting is rapidly expanding. In Bloomsbury DHA, for example, the numbers of cases doubled over the years 1989-90. There will be financial problems, therefore, if allocations are made on the basis of numbers of AIDS cases at the beginning of a financial year. Projected mid-year numbers must surely be used instead.

\section{Managing the expanding HIV epidemic}

The rapidly expanding HIV epidemic places the specialist centres for treatment of the disease in a unique position in the new environment. Rather than competing for patients and contracts, they are going to have to find ways of diverting patients to other centres, or be swamped. Using the preferred estimates from the Day Report, ${ }^{8}$ it has been calculated that if the major centres maintain their "market share" of AIDS patients, that it would result in a tripling of the numbers under care.

The new "market" environment will tend to put severe limits on the expansion of services and facilities, such as beds, which will be available to AIDS patients. Units will not be prepared to "lose" beds for urgent and unplanned admissions of acute AIDS related disease, when they would otherwise be filled with planned admissions under other more lucrative contracts.

However, because the basis of patient contact is self-referral, it will not be possible to adjust flows by manipulating contracting. In true "market" style, the potential overcrowding of certain clinics would self-regulate eventually, but it would be unacceptable to depend on deteriorating standards of care to force changes in patterns of self referral.

If the market forces leading clients to self-refer in certain ways are to be manipulated, detailed market research would be desirable. In the absence of this, it might be predicted that there are three main reasons contributing to the decision of a client to attend a particular clinic.

\section{(1) Accessibility}

The recommendations of the Monks Working Party report, endorsed by the Department of Health, should lead to local provision of GUM and AIDS/ HIV services in all districts. However, if there is to be a significant diversion of clients from the main centres, other elements of the recommendations will have to be acted upon. In particular, if mobile "commuter" clients currently using inner city clinics during the working day are to be persuaded to utilise clinics in their district of residence, more clinics must be persuaded to hold sessions in the evening and at weekends.

\section{(2) Acceptability}

There are a number of interlinked factors which contribute to the reputation and "acceptability" of services for clients:

(i) Knowledge and skills concerning HIV disease and its treatment are currently rather concentrated on the main centres, where most clients attend, and consequently where most experience has been gained and where most studies and trials are carried out. It is vital that these centres continue to develop the knowledge, skills and service delivery systems necessary to combat the disease. However, it is equally important that these centres take on the responsibility for rolling these out to nonspecialist centres and practitioners. The major centres must, therefore, be given the resources 
to enable them to pass on their knowledge and skills through formal training courses, seminars and published materials, and also in on-the-job training through training posts and rotations, shared care and specialist outreach teams. Practitioners from non-specialist services and centres should be encouraged and helped to take up on these training opportunities and facilities, and to update and maintain their standards through continuing education.

(ii) Professional staff reputations are gained with certain client groups, either as a result of their professional stature, media profile, etc, or through their local reputation for good interpersonal skills. Staff working in smaller, more peripheral units, on the other hand, may not be able to generate such a reputation because of their lower profile and relatively less exposure. This problem could be mitigated against by arranging regular exchanges of staff between specialist and non-specialist centres.

(iii) Availability of the best or latest technology, drugs and delivery systems is important to the generally well informed clientele. Accordingly, they vote with their feet when one centre has and another centre has not. This applies equally well to equipment (for example, CD4 counter, MRI scanner) and participation in drug trials (such as, Concorde, DDI). These factors could be utilised to manipulate flows by: (a) ensuring that developing district centres either have new technologies themselves, or negotiated (and publicised) direct access to them on other sites. (b) trying to involve developing district centres in major drug trials. This would require close collaboration with the major centres, which in itself would be beneficial. The trials themselves would also benefit from the opportunity to compare efficacy with effectiveness.

\section{CHANGING PATIENT PRIORITIES WITH PROGRESSING HIV INFECTION}
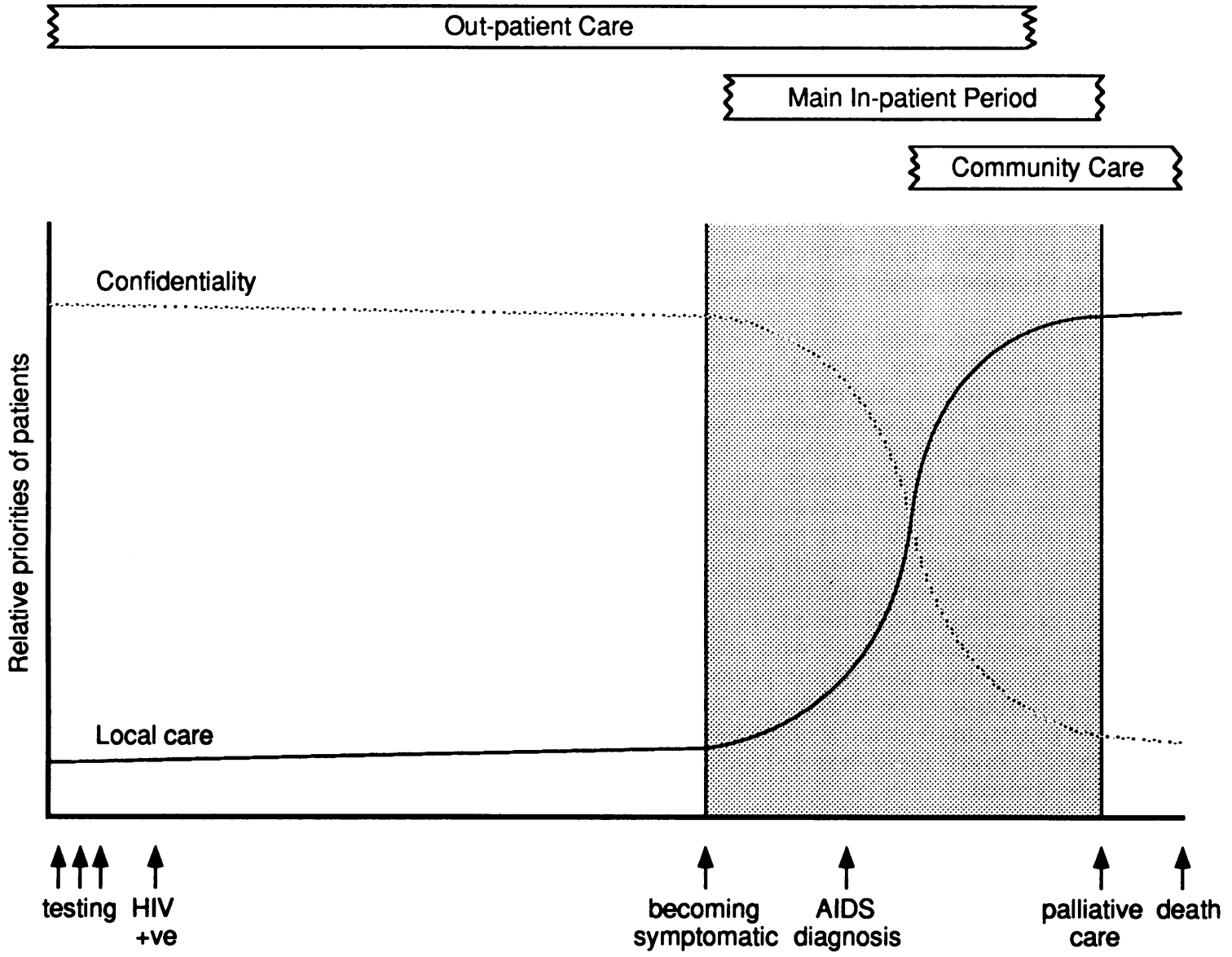

Figure Changing patient priorities with progressing HIV infection. 
(iv) The voluntary agencies and client support groups are instrumental in generating and maintaining the reputation of services. Individual clinics are named in their literature, on telephone "hotlines" and in face-to-face contacts. It is, therefore, vital that agencies such as the Terrence Higgins Trust, Frontliners, Positively Women, etc, are involved from the outset in any strategy to develop services in the current nonspecialist centres.

\section{(3) Anonymity}

Even if the problems of accessibility and acceptability could be solved completely, it is likely that the major inner-city HIV/AIDS centres will continue to attract a large proportion of HIV/AIDS patients in the foreseeable future. This is because, certainly in the early months and years after discovering their infection, most patients wish to maintain anonymity. This is replaced as a priority as they become symptomatic by the desire to spend less time travelling, and to have as much of their illness as possible managed in the community or at home (see fig). Neither of these basic trends are likely to change in the foreseeable future. The only area where some change of behaviour may be possible, therefore, is represented by the stippled area in the figure. It may be possible with counselling, facilitation and support to persuade patients to transfer significant parts of their care and follow up to their home district earlier, effectively moving the cross-over point on the graph to the left. Only in this way can some of the treatment and care burden be shifted from the current major specialist AIDS centres to the less specialised district providers.

It becomes apparent, when studying the possible strategies for manipulating referral patterns for patients with HIV infection, that the process must be coordinated. Market forces alone cannot be left to drive change. At the basis of this change there will have to be the capacity for money not only to "follow" patients, but also to precede them. Since the need to maintain confidentiality precludes sending information about patient episodes across boundaries, all such adjustments must be made on the basis of aggregated data only. If this is to be achieved there are two important provisos with respect to funding. Firstly, at least part of the payment for services must continue to be ring-fenced, so as to allow for the geographical inequity of the burden of care. Secondly, a much more flexible funding formula must be devised.
There is no doubt that in the 1980 s GenitoUrinary Medicine benefitted greatly from the attention and additional funding generated by the epidemic of HIV/AIDS. However, it will be apparent from the discussions above that the main problems for the specialty in the new environment will actually relate to work generated by clients with HIV infection. The main threat is, of course, that funding of HIV services will not keep pace with the increasing numbers. If this happens and clients with HIV infection increasingly dominate GUM clinics without resources for treatment expanding accordingly, patients with other sexually transmitted diseases will be faced with a rapidly dwindling service. This will be disastrous for both personal and public health. It would seem sensible, therefore, to use the business planning process to establish, where appropriate, separately funded "block" contracts for general GUM services and HIV services. In this way expansion of one can be accounted for without it being to the detriment of the other.

It is hoped that, in general, the process of contracting will bring an increased focus on quality assurance. This may well be true, but as far as the GUM service is concerned there can be no improvement in quality unless we can also guarantee the "width".

Address correspondence to Dr C Bentley.

1 Department of Health. Working for Patients. HMSO, Dec. 1988.

2 NHS Management Executive. Working for Patients "Contracts for Health Services: Operating Contracts". EL(90)MB/24. Feb. 1990.

3 Department of Health. District Allocations. EL(90)MB/22. Feb. 1990.

4 NHS Management Executive. Working for Patients "Contracts for Health Services: Operational Principles”. EL(89)MB/169 Sept. 1989.

5 House of Lords Official Report (Hansard). Vol. 520 No 107 135259. $25 / 7 / 90$

6 Monks Working Party. Report of the Working Group to Examine Workloads in Genito Urinary Medicine Clinics. Department of Health Nov. 1988.

7 Department of Health. AIDS and HIV: Service Objectives 1990/91. Annex to EL:(90)P/30. February 1990.

8 NHS Management Executive. Working for Patients "Pricing Contracts". EL(89)MB/130 July 1989 .

9 Day NE, Anderson RM, Daykin CD, et al. Report of a Working Group convened by the Director of the Public Health Laboratory Service. "Acquired Immune Deficiency Syndrome in England and Wales to end 1993 Projections Using Data to end September 1989". Communicable Disease Report. January 1990

Accepted for publication 21 December 1990. 